\title{
El rol del Tribunal de Justicia de la Comunidad Andina en los 50 años de integración subregional
}

Gustavo García Brito*(D)

\section{Resumen}

La Comunidad Andina es una comunidad de derecho con un alto grado de institucionalización y legalización. El objetivo del trabajo es evaluar el rol del Tribunal Andino en relación con el establecimiento y la consolidación del mercado ampliado, a través del Programa de Liberación y la armonización gradual de políticas económicas, especialmente en materia de propiedad intelectual. Al efecto, se desarrolló una matriz de análisis empírico sobre la base de los principales pronunciamientos de ese órgano jurisdiccional divididos en tres bloques temporales. Así, se concluye que el Tribunal Andino ha desempeñado diversos roles, estableciendo las bases del derecho comunitario y del propio proceso de integración, definiendo los contornos de los principales mecanismos para la consolidación de un mercado ampliado y coadyuvando con la armonización de políticas económicas.

Palabras clave: Integración económica regional, Comunidad Andina, Tribunal Andino, Institucionalización, Judicialización.

\section{The role of the Court of Justice of the Andean Community in the 50 years of subregional integration}

\begin{abstract}
The Andean Community is a community of law with a high degree of institutionalization and legalization. This research aims to evaluate the role of the Andean Court in the establishment and consolidation of the Andean market, through the Liberation Program and the gradual harmonization of economic policies, especially regarding intellectual property. To this end, an empirical analysis matrix was developed based on the main pronouncements of that Court divided into three time blocks. Thus, this study concluded that the Andean Court has played various roles, establishing the bases of the community's law and of the integration process
\end{abstract}

* Magistrado del Tribunal de Justicia de la Comunidad Andina. Doctorando del Departamento de Estudios Internacionales de la Facultad Latinoamericana de Estudios Sociales (FLACSO) Sede Ecuador. El artículo constituye un avance de la investigación doctoral que está desarrollando el autor. ‘ggarcia@ tribunalandino.org>.

Recibido: 25 de junio de 2020 | Revisado: 9 de julio de 2020 | Aceptado: 19 de agosto de 2020. Para citar este artículo: García Brito, Gustavo. "El rol del Tribunal de Justicia de la Comunidad Andina en los 50 años de integración subregional”. Comentario Internacional 20 (2020): 167-199. doi: 10.32719/26312549.2020.20.1.6 
itself, defining the outlines of the main mechanisms for the consolidation of the Andean market and collaborating to the harmonization of economic policies.

Keywords: Regional economic integration, Andean Community, Andean Court, institutionalization, judicialization.

\section{Introducción}

a firma del Acuerdo de Integración Subregional en 1969, el cual pasó a denominarse posteriormente como Acuerdo de Cartagena, ${ }^{1}$ representa la visión que tenían Bolivia, Chile, Colombia, Ecuador y Perú en cuanto a su estrategia de política exterior económica y comercial en ese momento histórico. Al respecto, de una lectura de los dos primeros artículos de ese instrumento, claramente se puede observar que el recién inaugurado proceso de integración subregional andino era considerado como un medio, un mecanismo o un instrumento para alcanzar propósitos mayores como el desarrollo equilibrado y armónico, la aceleración de los niveles de crecimiento económico y la reducción de diferencias entre los países que lo componen.

Del mismo modo, con la finalidad de alcanzar los objetivos propuestos, los países andinos establecieron en el artículo 3 del citado Acuerdo una serie de mecanismos y medidas que permanecen vigentes hasta la fecha:

a) La armonización de políticas económicas y sociales y la aproximación de las legislaciones nacionales en las materias pertinentes;

b) La programación conjunta, la intensificación del proceso de industrialización subregional y la ejecución de Programas Sectoriales de Desarrollo Industrial;

c) Un programa de Liberación del intercambio más acelerado que el que se adopte en general en el marco de la ALALC;

d) Un Arancel Externo Común, cuya etapa previa será la adopción de un Arancel Externo Mínimo Común;

e) Programas destinados a acelerar el desarrollo del sector agropecuario;

1. Por mandato de la Decisión 1 de la Comisión del Acuerdo de Cartagena.

2. Si bien Venezuela participó en las negociaciones para su constitución, recién se adhirió al bloque en 1973. 
f) La canalización de recursos de dentro y fuera de la Subregión para proveer a la financiación de las inversiones que sean necesarias en el proceso de integración;

g) La integración física; y

h) Tratamientos preferencial a favor de Bolivia y el Ecuador.

Al margen de estos mecanismos, el Acuerdo de Cartagena, en actual vigencia, codificado mediante la Decisión 563 de la Comisión de la Comunidad Andina establece tres adicionales: i) Profundización de la integración con los demás bloques económicos regionales y de relacionamiento con esquemas extra regionales, ii) Programas para acelerar el desarrollo del sector agroindustrial; y, iii) Programas en el campo de los servicios y la liberación del comercio intra subregional de servicios.

Como se puede apreciar, se planteó una ambiciosa agenda que tenía que ser instrumentalizada por la Comisión del Acuerdo de Cartagena, la cual contaría con el apoyo técnico de la Junta del Acuerdo de Cartagena (en adelante, la Junta). En relación con los mecanismos planteados, es fácil advertir que guardan relación con las primeras cuatro formas o etapas de la integración económica identificadas por Balassa. Este autor planteaba que la integración consistía en la "supresión de la discriminación entre unidades económicas de diferentes países", 3 la cual avanzaba de forma gradual. Así, se tendrían que celebrar acuerdos de preferencias arancelarias, posteriormente se establecerían zonas de libre comercio, uniones aduaneras, un mercado común, hasta llegar al establecimiento de una unión económica y a un esquema de integración completa.

Cabe señalar que, en este primer momento del proceso, se trataba de una instancia intergubernamental puesto que, por ejemplo, las normas adoptadas por la Comisión debían ser incorporadas por los Países Miembros a su legislación nacional. Es decir, aun no gozaban de aplicación inmediata y tampoco generaban eficacia directa. ${ }^{4}$ Por otra parte, en ese momento aún no existía un Tribunal de Justicia que velara por el cumplimiento de los compromisos asumidos por los Países Miembros.

3. Bela Balassa, The Theory of Economic Integration (New York: Routledge, 1961), 161.

4. Un ejemplo de lo señalado es que en el artículo "A" de las Disposiciones Transitorias de la Decisión 24 de la Comisión del Acuerdo de Cartagena "Régimen común de tratamiento a los capitales extranjeros y sobre marcas, patentes, licencias y regalías", se disponía que la misma solo entraría en vigencia "cuando todos los Países Miembros hayan depositado en la Secretaría de la Junta los instrumentos por los cuales lo pongan en práctica en sus respectivos territorios". 
Esta etapa es conocida como la primera ola de regionalismo en el continente, la cual promovía el desarrollo endógeno de los países a través de la industrialización sustitutiva de importaciones (ISI) y la profundización de las relaciones comerciales entre socios, con miras a la conformación de un mercado ampliado. La aplicación de este modelo no tuvo los resultados esperados y los propios precursores de su implementación sugirieron reformas. ${ }^{5}$ Uno de los aspectos que causó este escenario negativo en el ámbito andino fue la falta de consenso entre los Países Miembros sobre la obligatoriedad de los compromisos asumidos, así como la ausencia de una institución que ejerciera el control sobre su cumplimiento.

En ese sentido, después de un proceso iniciado por la Junta ${ }^{6}$ y tomando en cuenta la Declaración de los Presidentes de los Países Miembros, suscrita en Bogotá el 8 de agosto de 1978, en la que señalaron expresamente que el avance de la integración andina demuestra:

la impostergable necesidad de disponer de un órgano jurisdiccional que controle la legalidad de las normas emanadas de la Comisión y de la Junta, dirima las controversias sobre el cumplimiento de los Países Miembros e interprete los principios que conforman la estructura jurídica del Acuerdo. ${ }^{?}$

El 28 de mayo de 1979 se firmó el Tratado de Creación del Tribunal de Justicia del Acuerdo de Cartagena el cual, después de un largo proceso de ratificación, entró en vigencia el 19 de mayo de 1983. Posteriormente, el 2 de enero de 1984, el recién creado Tribunal se instaló en la ciudad de Quito-Ecuador, y los cinco primeros Magistrados ${ }^{8}$ iniciaron su labor misional de administrar justicia en la subregión andina.

5. Ver Raúl Prebisch, Hacia una dinámica del desarrollo latinoamericano: con un apéndice sobre. El falso dilema entre desarrollo económico y estabilidad monetaria. (México: Fondo de Cultura Económica, 1963), 8 sobre las consecuencias negativas de la industrialización en compartimentos estancos. Ver, Celso Furtado, "Dependencia externa y teoría económica". El trimestre económico 38, n.ำ 150 (1971):335-349, sobre el incremento de inversión en el sector industrial exportador que modifica las condiciones de producción y eleva su nivel tecnológico.

6. A través del documento titulado "Informe y las Bases de un Tratado para la creación del Tribunal de Justicia del Acuerdo de Cartagena" de 11 de diciembre de 1972, que daría lugar posteriormente a la Propuesta 43 de la Junta, presentada en 1974, la cual incluía un proyecto de Tratado.

7. Acta Final del XXIV Período de Sesiones Ordinarias de la Comisión del Acuerdo de Cartagena, celebrado entre el 17 de abril y el 15 de agosto de 1978.

8. Hugo Poppe Entrambasaguas (Bolivia), Luis Carlos Sáchica (Colombia), Estuardo Hurtado Larrea (Ecuador), Gonzalo Ortiz de Zeballos (Perú) y José Guillermo Andueza Acuña (Venezuela). 
Los cinco primeros artículos del Tratado de Creación se refieren al ordenamiento jurídico del proceso de integración, estableciendo su sistema de fuentes, así como sus características esenciales de obligatoriedad, aplicación inmediata y efecto directo; y, consagrando el denominado principio de cooperación leal. ${ }^{9}$ Por el cual, los Países Miembros asumen la obligación positiva (de hacer) en relación con la adopción de todas las medidas necesarias para asegurar el cumplimiento de los compromisos previstos en la normativa andina, y la obligación negativa (de no hacer), por lo que queda proscrita la adopción de medidas nacionales contrarias al nuevo ordenamiento jurídico comunitario, o inclusive aquellas que obstaculicen su aplicación.

A partir del artículo 6 del Tratado se encuentran las regulaciones sobre la creación y organización de esta Corte Internacional, y a partir del artículo 17 las referidas al ejercicio de las tres competencias atribuidas, en ese momento, por los Países Miembros: i) Acción de Nulidad (Control de legalidad de los actos de la Comisión y la Junta), ii) Acción de Incumplimiento (Control sobre el cumplimiento de los compromisos y obligaciones de los Países Miembros); e, iii) Interpretación Prejudicial (Garantía de interpretación y aplicación uniforme de las normas que conforman el ordenamiento jurídico comunitario andino). Por último, pero no menos importante, en el artículo 33 se establece claramente que el Tribunal cuenta con jurisdicción exclusiva y excluyente para resolver las controversias que surjan con motivo de la aplicación del ordenamiento jurídico comunitario andino.

La entrada en vigencia del Tratado de Creación del Tribunal constituye el punto de partida de una nueva Comunidad de Derecho ${ }^{10}$ y el cambio de paradigma en la región andina hacia la supranacionalidad. En ese contexto corresponde evaluar el rol que tuvo y tiene el ordenamiento jurídico comunitario andino, por una parte, y el hoy denominado Tribunal de Justicia de la Comunidad Andina (en adelante, el Tribunal o el TJCA) -en cuanto órgano de control de la legalidad, cumplimiento, e interpretación y aplicación uniforme de las normas andinas-, por otra, en relación con el establecimiento y la consolidación de los mecanismos previstos en el artículo

9. Previsto inicialmente en el Artículo 5 del Tratado de Creación del Tribunal de Justicia del Acuerdo de Cartagena, hoy Artículo 4 del Tratado de Creación del Tribunal de Justicia de la Comunidad Andina.

10. Sobre el particular, se puede ver: Alberto Zelada Castedo, Derecho de la integración económica regional (Buenos Aires: Ediciones de Palma, 1982); Luis. Sáchica, Introducción al derecho comunitario andino (Bogotá: Temis, 1990); Galo Mantilla, Derecho andino (Quito: Tribunal de Justicia del Acuerdo de Cartagena, 1992); Jorge Quindimil, Instituciones y derecho de la Comunidad Andina (Valencia: Tirant lo blanch, 2006); Ricardo Vigil, La estructura jurídica y el futuro de la comunidad andina (Madrid: Civitas, 2011). 
3 del Acuerdo de Cartagena, especialmente el Programa de Liberación y la armonización gradual de políticas económicas, tomando como ejemplo el régimen común de propiedad industrial.

Al efecto, cabe recordar que, tal como señala Vivares ${ }^{11}$ las principales explicaciones sobre la constitución y el funcionamiento de la integración regional en América Latina, entendida como un "proceso formalizado y conducido desde el estado", ${ }^{12}$ provienen fundamentalmente de los enfoques de la teoría de la integración económica regional ${ }^{13}$ y del institucionalismo neoliberal. ${ }^{14}$ No obstante, ambas perspectivas presentan, entre otras, las siguientes limitaciones: i) Responden a una visión preponderantemente sistémica y coyuntural que toma en cuenta únicamente la oferta del sistema -económico y comercial global- así como el rol que jugarían las instituciones supranacionales, sin considerar las demandas internas que enfrentan los Estados; ${ }^{15}$ ii) Se presenta a la integración regional como una estrategia anclada únicamente en aspectos económicos que relativiza la incidencia de los aspectos políticos, jurídicos y sociales, tanto en el nivel interno como

11. Ernesto Vivares, Paul Torres y Kristina Cvetich, "Enfoques y cárceles conceptuales en el entendimiento de los Nuevos Regionalismos Latinoamericanos", En Desafíos estratégicos del regionalismo contemporáneo: CELAC e Iberoamérica, ed. Adrián Bonilla e Isabel Álvarez (San José: FLACSO, 2014), 20-1.

12. Andrés Malamud, "Conceptos, teorías y debates sobre la integración regional" (ponencia, V Congreso Latinoamericano de Ciencia Política, Buenos Aires, 28 al 30 de julio de 2010).

13. Al respecto, se puede ver: Balassa, The Theory of Economic Integration; Ernst Haas, "The study of regional integration: reflections on the joy and anguish of pretheorizing", International organization $24, \mathrm{n} .{ }^{\circ} 4$ (1970): 607-46; Lawrence Summers, "Regionalism and the world trading system", Policy implications of trade and currency zones (1991):295-301; Clark Reynolds, Fransico Thoumi y Reinhart Wettmann. A Case for Open Regionalism in the Andes. Policy Implications of Andean Integration in a Period of Hemispheric Liberalization and Structural Adjustment (Washington: USAID / Friedrich Ebert Stiftung, 1995); Primo Braga, Raed Safadi y Alexander Yeats, "Regional integration in the Americas: deja vu all over again?", The World Economy 17, n. 4 (1994): 577-602; Chad Bown, et.al, Mejores vecinos. Hacia una renovación de la integración económica en América Latina (Washington D.C.: Banco Mundial, 2017).

14. Sobre el particular, se puede ver: Joseph Nye, "Comparative regional integration: Concept and measurement", International organization 22, n. ${ }^{\circ}$ (1968): 855-80; Stephen Krasner, "State power and the structure of international trade", World politics: A quarterly journal of international relations 28, n. 3 (1976): 317-47; Robert Keohane, "Cooperation and international regimes", en After Hegemony: Cooperation and Discord in the World Political Economy, 49-13 (New Jersey: Princeton University Press, 1984); Comisión Económica para América Latina, El regionalismo abierto en América Latina y el Caribe: la integración económica al servicio de la transformación productiva con equidad (Santiago de Chile: CEPAL, 1994); Edward Mansfield y Helen Milner, ed, The political economy of regionalism (Columbia: Columbia University Press, 1997); Wilfred Ethier, "The New Regionalism", The Economic Journal 108, n. ${ }^{\circ} 449$ (1998): 1149 61; Walter Mattli, The logic of regional integration: Europe and beyond (Cambridge : Cambridge University Press, 1999); Mikio Kuwayama, Open regionalism in Asia Pacific and Latin America: a survey of the literature (Santiago de Chile: CEPAL, 1999).

15. Walter Mattli, The logic of regional integration: Europe and beyond (Cambridge : Cambridge University Press, 1999), 17. 
en el concierto regional; iii) El predominio del enfoque prescriptivo que proponen estudios como el de la CEPAL (1994), Kuwayama (1999), Devlin y Estevadeordal (2001), o el Banco Mundial (2000), entre otros, generó una matriz de análisis evolutiva, lineal y homogénea que condicionó la evaluación sobre el éxito o fracaso de la integración regional.

En consecuencia y, con el propósito de ofrecer un punto de partida distinto, el trabajo parte de la premisa de que en el proceso de integración subregional andino existe un alto grado de legalización, de conformidad con el marco analítico propuesto por Kenneth W. Abbott, et al. ${ }^{16}$ Estos autores explican que la relación entre derecho y política "es recíproca y [es] mediada por instituciones". En ese sentido, "la legalización internacional es una forma de institucionalización" que presenta tres dimensiones: (i) Obligación: El grado de compromiso que asumen los Estados; (ii) Precisión: El contenido y alcance de las reglas que regulan las conductas de los Estados; y, (iii) Delegación: La medida en la que los Estados otorgan autoridad a terceros para elaborar reglas, interpretarlas y aplicarlas, lo que incluye a los mecanismos de solución de controversias.

Sobre esa base, los autores elaboran una tipología de instituciones legalizadas que identifica: a) la legalización completa (dura), en la cual las tres dimensiones son altas; b) diferentes formas de legalización parcial (suave); y, c) instituciones sin legalización. Desde la perspectiva de Kenneth W. Abbott, et al. (2000), la legalización contribuye a que los Estados y otros actores resuelvan los problemas relacionados con el cumplimiento de sus obligaciones internacionales, reduzcan los costos de transacción y amplíen continuamente sus compromisos.

En el caso de la Comunidad Andina, las normas fundamentales, constitutivas o de derecho primario, -el Acuerdo de Cartagena y el Tratado de Creación del Tribunal de Justicia de la Comunidad Andina, sus Protocolos e Instrumentos adicionales; así como los demás tratados suscritos y ratificados por los Países Miembros en materia de integración comunitaria andina-.así como las normas derivadas o de derecho secundario- las Decisiones del Consejo Andino de Ministros de Relaciones Exteriores y la Comisión de la Comunidad Andina; las Resoluciones de la Secretaría General de la Comunidad Andina; y, los Convenios de Complementación Industrial y otros que adopten los Países Miembros entre sí y en el marco del proceso de

16. Kenneth Abbott, et al, "The concept of legalization", International organization 54, n. 3 (2000): 401-419. 
la integración subregional andina- que forman parte del ordenamiento jurídico comunitario andino, imponen obligaciones vinculantes para los Países Miembros, incluidas naturalmente todas las autoridades administrativas y jurisdiccionales nacionales.

Este sistema de fuentes establece además, con suficiente precisión y de forma clara e inequivoca, las reglas de comportamiento que deben seguir los Estados, las administraciones nacionales, así como los órganos e instituciones del Sistema Andino de Integración; y, por último a partir de 1979, se delegó el control de legalidad, cumplimiento y de interpretación y aplicación uniforme de la normativa andina a un Tribunal de Justicia de carácter permanente, supranacional y comunitario, cuyas sentencias son además de obligatorio cumplimiento.

De esta manera, en las próximas páginas se realizará un análisis empírico acerca del rol que cumplió este órgano jurisdiccional durante sus primeros treinta y cinco años de efectivo funcionamiento. El objetivo central es desarrollar una matriz de análisis dinámica que permita identificar los avances y retrocesos del Programa de Liberación y, de la armonización de políticas económicas, específicamente en materia de propiedad industrial, en la Comunidad Andina.

Para el efecto, se reconoce que han existido diferentes niveles de cumplimiento de los compromisos y obligaciones asumidas por los países miembros; así como, en el grado de participación de los actores públicos y privados, específicamente en el momento de activar los mecanismos judiciales de control ante sus autoridades locales y ante el Tribunal Andino.

En ese sentido, se estudiarán los principales pronunciamientos del órgano jurisdiccional divididos en tres bloques temporales: el primero que va desde 1984, año en el que se iniciaron efectivamente sus actividades, hasta 1995 que fue la última gestión antes del inicio de los cambios institucionales promovidos por la firma del Protocolo de Trujillo.

Este período inicial se caracteriza por una escasa actividad en el que ni los países miembros ni la Junta iniciaron Acciones de Incumplimiento, se tramitaron cuatro acciones de nulidad ${ }^{17}$ y se emitieron cuarenta Interpreta-

17. Procesos $1-\mathrm{N}-85,1$ y 2-N-86, y 4-N-92. Si bien, durante ese período se recibieron en total siete demandas en Acción de Nulidad, en los procesos 1 y 2-N-92, el Tribunal rechazó in límine la demanda por ausencia de legitimación activa en el primer caso y, por carecer de competencia, en el segundo. Asimismo, en el proceso 3-N-92 se declaró inadmisible la demanda. 
ciones Prejudiciales. En ese lapso, Bolivia, Perú y Venezuela no utilizaron el Sistema Andino de Solución de Controversias.

El segundo período está comprendido entre 1996, año en el que se suscribió el Protocolo de Trujillo modificatorio del Acuerdo de Cartagena por el cual se dio inicio a una nueva fase del proceso integrador y en el que se presentó además la primera Acción de Incumplimiento ante el Tribunal y el año 2006, en que la República Bolivariana de Venezuela decidió retirarse del proceso de integración, hecho que marca un punto de inflexión en la Subregión. Durante esta segunda década, la recién denominada Comunidad Andina vivió el período de mayor efervescencia, actividad y desarrollo normativo.

En 1998 se firmó el Protocolo de Cochabamba, por el cual se modificó el Tratado de Creación del TJCA, con importantes reformas como el mayor acceso de particulares al sistema mediante la acción de incumplimiento y el establecimiento de tres nuevas competencias: i) Recurso por Omisión, ii) Jurisdicción Laboral, y la iii) Función Arbitral. Durante esos diez años, se recibieron noventa y dos demandas en Acción de Incumplimiento -la gran mayoría propuestas por la Secretaría General de la Comunidad Andina-, treinta y cinco Acciones de nulidad, y mil ciento treinta y dos solicitudes de Interpretación Prejudicial.

Por último, el tercer período está constituido por los años comprendidos entre 2007 y 2019, en los que se puede observar una considerable reducción de la utilización del Sistema Andino de Solución de Controversias por parte de los Países Miembros y, sobre todo, por parte de la Secretaría General de la Comunidad Andina que presentó únicamente dos demandas en Acción de incumplimiento, una en el año 2007 y, la última, en el año 2008.

Por otra parte, en ese mismo período de tiempo, se incrementó el acceso de los particulares a las Acciones de Incumplimiento y Nulidad, así como aumentó considerablemente el número de consultas de Interpretación Prejudicial -que durante esos doce años alcanzaron la cifra de 4.701aspecto que evidencia un incremento exponencial de las causas tramitadas por el Tribunal, las cuales se han cuadruplicado en relación con el período anterior. Sobre el particular, merece destacarse la activa participación de las autoridades nacionales de los cuatro países miembros, pues (Perú primero y Bolivia después) se incorporaron definitivamente a la dinámica del Sistema Andino de Solución de Controversias gracias, especialmente, a la 
ardua labor de difusión del ordenamiento jurídico comunitario desarrollada por el TJCA en esos países.

\section{Primer período (1984 - 1995)}

La República de Colombia fue el primer país en acudir al Tribunal de forma directa, mediante el inicio de cuatro acciones de nulidad -las únicas planteadas entre 1985 y 1995- contra Resoluciones emitidas por la Junta. Las tres primeras demandas estaban vinculadas con la definición del objeto y alcance del Programa de Liberación y con las excepciones a su aplicación en la forma de reservas o a través de la aplicación de salvaguardias temporales.

Por otra parte, fue el Consejo de Estado de la República de Colombia el primer órgano judicial nacional en formular consultas de Interpretación Prejudicial y el responsable de motivar treinta y un de las cuarenta Interpretaciones Prejudiciales emitidas por el Tribunal durante la primera década de funcionamiento; veintinueve de las cuales se referían a temas vinculados con el régimen común de propiedad industrial.

Merece destacarse también que, en ese mismo período, se recibieron dos consultas de la Corte Suprema de Justicia (Procesos 2-IP-88 y 2-IP-80) y una de la Corte Constitucional (Proceso 10-IP-94) de Colombia, en el marco de acciones de control de constitucionalidad de normas nacionales que serían contrarías a la normativa andina sobre propiedad intelectual. Del mismo modo, el Tribunal Contencioso Administrativo del Departamento del Norte de Santander -con sede en Cúcuta, en la República de Colombia- planteó dos consultas (Procesos 1-IP-90 y 3-IP-93) dentro de acciones de incumplimiento iniciadas por particulares contra dicho país por la supuesta vulneración de normas andinas relacionadas con el Programa de Liberación.

Sobre el particular, cabe señalar que una de las empresas ${ }^{18}$ que promovió la primera acción de incumplimiento en sede nacional es la misma que años antes (en 1987) había presentado una demanda en acción de incumplimiento ante el Tribunal Andino; la cual fue rechazada in límine, pues en ese momento, el inicio de dicha acción estaba reservado para los Países Miembros y la Junta.

18. Aluminio Reynolds S.A. 
Por último, corresponde mencionar que la República del Ecuador, a través del Tribunal Distrital $\mathrm{N}^{\circ} 1$ de lo Contencioso Administrativo de Quito, formuló cuatro solicitudes (Procesos 2, 3 y 6-IP-96, y 17-IP-95), todas relacionadas con temas de propiedad intelectual.

Esta primera imagen nos permite realizar algunas apreciaciones sobre este primer período o fase:

- Inexistencia de control judicial sobre el cumplimiento de las obligaciones y compromisos de los Países Miembros del Acuerdo de Cartagena durante los primeros veinticinco años del proceso de integración. En los primeros diez años por ausencia de un órgano jurisdiccional con competencia para ello y, en los quince años posteriores, en virtud de una especie de acuerdo voluntario de los países para no presentar demandas, al cual se refiere Salazar y que pretendió ser instrumentalizado mediante la Decisión 301 de la Comisión del Acuerdo de Cartagena, cuyo artículo 13 establecía: "Sin perjuicio de lo establecido en el Tratado que crea el Tribunal de Justicia del Acuerdo de Cartagena, antes del 31 de diciembre de 1991 los Países Miembros establecerán un mecanismo informal y flexible para la solución de controversias con respecto a los incumplimientos que afectan el comercio intrasubregional." 19

- Inexistencia de control de legalidad sobre actos normativos de efectos generales de la Comisión, toda vez que durante este primer período no se presentó ninguna demanda de nulidad contra una Decisión, y un escaso control efectuado sobre actos administrativos de efectos particulares emitidos por la Junta. Dichos actos estaban referidos a la capacidad de un País Miembro -Colombia- de exceptuarse del cumplimiento del Programa de Liberación en relación con algunos productos (aluminio y derivados) y países (Ecuador y Venezuela).

- Demostración de un interés inicial de los particulares por acceder al control de cumplimiento y legalidad del Tribunal Andino, el cual fue rápidamente aplacado por el propio Tribunal con el rechazo de las demandas propuestas, en consideración a las limitaciones normativas relacionadas con la legitimidad activa para iniciar acciones.

19. Roberto Salazar Manrique, "El derecho Comunitario Andino: de la teoría Jurídica a la realidad actuante del derecho", Revista Jurídica, n. 9 (1994): 273. 
- Predominio de consultas de Interpretación Prejudicial vinculadas con la normativa andina sobre propiedad intelectual ( $90 \%$ del total) en el marco de procesos contencioso administrativos, a través de los cuales se demandaba la nulidad de actos emitidos por la oficina nacional competente de Colombia y, en menor medida del Ecuador, en los que se concedía o rechazaba el privilegio de patente o los derechos de exclusiva sobre marcas y otros signos distintivos. En el 60\% de esos procesos participaron empresas o sociedades extranjeras o extracomunitarias, $y$ en el $40 \%$ de los casos se discutían los derechos de empresas andinas, esencialmente colombianas. Esta dinámica se mantuvo inalterable a lo largo de los años y permanece en la actualidad.

Esta situación inicial generó una sensación de frustración en los miembros del órgano jurisdiccional, quienes fueron los primeros en proponer reformas a su Tratado de Creación con el propósito de optimizar y dinamizar su labor, entre otros, a través de la ampliación de la capacidad de los particulares para acudir al sistema andino de solución de controversias, tal como lo relata Quindimil. ${ }^{20}$ Esta iniciativa fue debidamente acogida por los Países Miembros y, tal como se mencionó, se hicieron importantes reformas a la norma constitutiva del Tribunal.

No obstante lo anterior, es evidente que en ese primer período, el Tribunal sentó las bases sobre los métodos funcionales que utilizaría para interpretar las normas del ordenamiento jurídico comunitario andino, privilegiando la interpretación teleológica y finalista de las normas andinas por sobre aquella literal y exegética. En ese sentido, fue construyendo paso a paso, sentencia a sentencia, y de manera muy cuidadosa, sistemática y ordenada, los pilares sobre los que se apoya -hasta el día de hoy- su jurisprudencia. A continuación, se destacan los principales pronunciamientos que dotaron de contenido y alcance a los conceptos e instituciones jurídicas básicas del derecho comunitario andino.

En la primera Interpretación Prejudicial emitida el 3 de diciembre de 1987, dentro del proceso 1-IP-87, el Tribunal se refirió a tres aspectos fundamentales:

20. Jorge Quindimil, Instituciones y derecho de la Comunidad Andina (Valencia: Tirant lo blanch, 2006), 34349. 
1. La armónica división de funciones y de colaboración que existe entre los jueces nacionales y el Tribunal Andino, en el marco de la jurisdicción comunitaria. A los primeros les corresponde pronunciarse sobre los hechos y apreciar los medios probatorios para fallar y decidir asuntos concretos aplicando las normas andinas y al segundo le compete, privativamente, la interpretación de las normas comunitarias.

2. La preeminencia del derecho andino como característica esencial de este nuevo ordenamiento jurídico, el cual "prevalece en su aplicación sobre las normas internas o nacionales" y como requisito básico para la construcción integracionista. En este punto corresponde anotar que el Tribunal dejó claramente establecido que este principio, conjuntamente con la autonomía, la aplicación inmediata y la eficacia directa de la normativa comunitaria alcanzaron "plena vigencia como norma jurídica, con la entrada en vigor del Tratado constitutivo del Tribunal a partir del 19 de mayo de 1983". Sobre el particular, resultan evidentes dos extremos: i) al margen del compromiso político asumido por los Países Miembros desde el inicio del proceso, las obligaciones contenidas en los Tratados y Decisiones no eran jurídicamente vinculantes y, en consecuencia, tampoco judicialmente exigibles antes de la entrada en vigencia del Tratado mencionado; y, ii) El cambio fundamental en el proceso hacia una efectiva judicialización y hacia una mayor delegación del ejercicio de competencias soberanas, que se traduce en el fundamento de la supranacionalidad.

3. La utilización preferente de los métodos de interpretación funcionales, como el método sistemático y el teleológico los cuales, según el Tribunal, adquieren una "connotación especial en el derecho comunitario como normativa de un proceso de realizaciones conjuntas para el logro de un objetivo común". Se resalta además la importancia y pertinencia de tomar en cuenta el objeto y fin de las normas, que en definitiva es la consolidación de la integración, a través del cumplimiento de los objetivos y la finalidad del proceso plasmados en el Acuerdo de Cartagena (Proceso 1-IP-87).

En la Sentencia de 25 de mayo de 1988, recaída en el proceso 2-IP-88, el Tribunal se refirió a los efectos de la normativa andina sobre los ordenamientos jurídicos nacionales, así como al desarrollo normativo interno del derecho comunitario: 
- En relación con el primer tema, el Tribunal señaló claramente que, en caso de conflicto, "la regla interna queda desplazada por la comunitaria, la cual se aplica preferentemente, ya que la competencia en tal caso corresponde a la Comunidad. En otros términos, la norma interna resulta inaplicable, en beneficio de la norma comunitaria" (énfasis agregado). Este pronunciamiento, más allá de reforzar la noción de preeminencia del derecho comunitario señalada anteriormente, reconoce expresamente los efectos del deslinde de competencias legislativas entre los órganos comunitarios y las autoridades nacionales, estableciendo con claridad que la delegación del ejercicio de una competencia soberana en favor de la Comunidad implica la reducción del margen de actuación y decisión política, jurídica y económica a nivel nacional. De forma complementaria, en un pronunciamiento posterior (Proceso 2-IP-90), el Tribunal señaló lo siguiente: "[...] para que el legislador nacional se vea desplazado, no basta que la comunidad se haya reservado el tratamiento normativo de un tema, en principio, ya que dicho desplazamiento solo se produce cuando el legislador comunitario ocupa efectivamente ese terreno con normas obligatorias para la Subregión".

Ahora bien, el propio Tribunal reconoce que se trata de "dos ordenamientos jurídicos distintos, autónomos y separados, que adoptan dentro de sus propias competencias formas peculiares de crear y extinguir el derecho, que por supuesto no son intercambiables" (Proceso 2-IP-88). Así, una norma andina no deroga automáticamente una disposición nacional, sino que, si existe incompatibilidad entre ellas, la segunda resulta inaplicable pese a continuar vigente, toda vez que los principios de aplicación inmediata y efecto directo del derecho comunitario inciden sobre el plano de eficacia de la norma nacional, y no así sobre su existencia o validez.

Al respecto, corresponde que las autoridades de los Países Miembros, actuando en consonancia con sus compromisos comunitarios, activen los mecanismos correspondientes para asegurar la compatibilidad y armonía entre estos dos sistemas normativos.

- En referencia al segundo tema, esta sentencia recoge por primera vez el principio del complemento indispensable en el ámbito andino; en virtud del cual se reconoce que, en algunos casos, los Países Miembros pueden adoptar medidas legislativas complementarias a las disposiciones comunitarias. Sobre el particular, advierte el órgano jurisdiccional que debe aplicarse un criterio restrictivo y que solo serán de recibo aquellas actua- 
ciones nacionales que sean "estrictamente necesarias para la ejecución de la norma comunitaria y, por tanto, que favorezcan su aplicación y que de ningún modo lo entraben o desvirtúen" (Proceso 2-IP-88).

Resulta evidente que la construcción del acervo normativo comunitario es un proceso dinámico y evolutivo. En ese sentido, la aplicación del citado principio cumple una función que podría asemejarse a la de un aceite en un sistema de engranajes de una compleja máquina industrial. Es decir, facilita y optimiza su adecuación y funcionamiento con el objetivo que la máquina -el proceso de integración- avance, no se detenga y cumpla su propósito.

Por otra parte, cuando los países deciden voluntaria y soberanamente embarcarse en un proceso integracionista, la consecuencia natural, lógica y deseable es que cumplan con los compromisos asumidos. ${ }^{21}$ El principio de cooperación leal, citado anteriormente, constituye precisamente una afirmación de lo mencionado. Fue con ocasión de la emisión de las sentencias en los procesos 2-N-86 (10 de junio de 1987) y 5-IP-89 (26 de octubre de 1989), que el Tribunal Andino tuvo la oportunidad de referirse a las dimensiones positiva (de hacer) y negativa (de no hacer) de dicho principio. En relación con la segunda, cabe destacar que los países miembros deben abstenerse de adoptar toda y cualquier medida que, "con cualquier nombre o forma [...] pueda obstaculizar la aplicación del ordenamiento jurídico andino, abstención imperativa inherente al cumplimiento de lo pactado y como soporte básico para el desarrollo del proceso de la integración”.

Esta declaración es la piedra angular del constructo jurisprudencial posterior sobre la intangibilidad del ordenamiento jurídico comunitario, especialmente en el ejercicio del control de cumplimiento que efectúa el Tribunal. En efecto, este órgano jurisdiccional llegó a afirmar, con posterioridad, que la vulneración de cualquier norma andina conlleva implícitamente la violación de este principio y, en consecuencia, afecta a la esencia misma del proceso de integración. ${ }^{22}$

21. Ver Ricardo Vigil, La estructura jurídica y el futuro de la comunidad andina (Madrid: Civitas, 2011), 59; César Montaño Galarza, Problemas constitucionales de la integración. (México D.F.: Universidad Anáhuac /Porrúa/Red Internacional de Juristas para la Integración Americana/Universidad Andina Simón Bolívar, 2013), 129.

22. Sobre el particular, el leading case fue la sentencia emitida en el proceso 3-AI-97. 


\section{Segundo período (1996 - 2006)}

\section{Hacia una nueva visión de la integración}

El 6 de marzo de 1996, la Junta del Acuerdo de Cartagena interpuso la primera acción de incumplimiento ante el Tribunal Andino. Es decir que, recién en esa fecha, casi quince años después de la suscripción del Tratado de su creación se activó por primera vez el mecanismo de solución de controversias con el propósito de que el órgano jurisdiccional supranacional efectúe el control de cumplimiento de los compromisos y obligaciones asumidas por un País Miembro - en ese caso, la República del Ecuador-. Merece destacarse que esa acción cambió radicalmente la dinámica de utilización del mecanismo mencionado para resolver controversias en la Subregión.

Si el período analizado anteriormente se caracteriza por la inacción, en la década comprendida entre 1996 y 2006, la Junta y luego la Secretaría General de la Comunidad Andina (en adelante, SGCA), iniciaron ochenta acciones de incumplimiento. En ese mismo período se recibieron dos acciones promovidas por Venezuela, una por Colombia y nueve por particulares. Es decir, noventa y dos acciones de esta naturaleza contra los cinco países miembros, la mayor cantidad en la historia del Tribunal. Entre 1996 y 2006 se demandó el supuesto incumplimiento de Bolivia en cuatro (4) oportunidades, de Colombia en diecisiete (17) casos, de Ecuador en veintiséis (26) procesos, de Perú en diecisiete (17) causas, y de Venezuela en veintiocho (28) oportunidades.

Al respecto, corresponde cuestionarse ¿cuál fue la conducta que motivó el cambio de acción de la Junta y la SGCA? ¿qué compromiso no estaba siendo cumplido? Para responder estas cuestiones, es necesario señalar que, si durante la primera fase de labor del Tribunal los temas relacionados con el Programa de Liberación y el Régimen Común de Propiedad Industrial fueron preponderantes, en esta segunda fase se mantuvo esa lógica, y en la primera acción de incumplimiento (Proceso 01-AI-96) se demandó que la República del Ecuador estaría incumpliendo dicho régimen al adoptar una norma nacional ${ }^{23}$ contraria a los principios y a las reglas previstas en la Decisión 344 de la Comisión del Acuerdo de Cartagena, vigente en esa fecha.

23. Decreto Ejecutivo No 1344 -A dictado el 21 de diciembre de 1993 y sus modificaciones introducidas por el Decreto $\mathrm{N}^{\circ} 1738$ del 30 de junio de 1994. 
El conflicto se produjo cuando la República del Ecuador modificó su normativa nacional de propiedad intelectual, a fin de adecuarla a un Convenio bilateral suscrito con Estados Unidos en $1993 .{ }^{24}$ La modificación legislativa permitía la concesión de las denominadas patentes pipeline ${ }^{25}$ en el territorio ecuatoriano, especialmente para productos farmacéuticos, situación contraria a lo dispuesto por la norma andina citada anteriormente; la cual establecía el requisito de la novedad absoluta o universal como elemento indispensable para otorgar el privilegio de patente en los países de la subregión andina. Esta tentativa de establecer unilateralmente una posibilidad de registro de patentes, que había sido proscrita por la Comisión del Acuerdo de Cartagena, fue declarada contraria al ordenamiento jurídico andino y el Ecuador tuvo que adecuar su conducta a la Sentencia emitida por el Tribunal.

El segundo caso planteado (Proceso 02-AI-96) estaba vinculado con ambas materias, pues Venezuela demandó que el Ecuador había establecido restricciones indebidas a la importación de cigarros marca Belmont, producidos por una empresa venezolana, contrariando así las obligaciones del Programa de Liberación, toda vez que dicha marca no estaba siendo utilizada en Ecuador.

A su turno, Ecuador alegaba que la prohibición de importación de los productos mencionados estaba amparada en el registro previo de dicha marca en su territorio, así como en las disposiciones de la Decisión 344 que regulaban los derechos de exclusiva del titular de ese registro, entre los que se encontraba el derecho a oponerse a la importación de productos que tengan la misma marca-. Al momento de resolver el caso, el Tribunal tomó en cuenta la necesidad de encontrar un equilibrio entre el principio de libre circulación de mercancías, que sirve de base al Programa de Liberación, y la protección de los derechos de propiedad industrial. Así, declaró que existió incumplimiento durante el tiempo en el que no existía justificación ni sustento para prohibir la importación, toda vez que no se había probado el uso de la marca en Ecuador.

24. Acuerdo sobre la Protección y el Cumplimiento de los Derechos de Propiedad Intelectual, firmado entre el Ecuador y los Estados Unidos el 15 de octubre de 1993.

25. En la demanda de la Junta, citada en la sentencia emitida por el TJCA en el proceso 01-AI-96 se define al pipeline como "un mecanismo de transición para conceder protección a productos que no eran patentables, en países que están modificando su normativa sobre patentes". 
No obstante, declaró también que ese incumplimiento había cesado una vez que se emitió un acto administrativo, debidamente motivado, por el que se verificó el uso de la marca en Ecuador y, en consecuencia, se probó la existencia de una legítima razón para prohibir dichas importaciones. Por último, el Tribunal exhortó al país demandado a aplicar "las medidas necesarias para el restablecimiento de los derechos de los particulares afectados por la situación de incumplimiento" (Proceso 02-AI-96).

Las siguientes acciones planteadas estaban relacionadas fundamentalmente con el incumplimiento de obligaciones vinculadas con el Programa de Liberación, el Sistema Andino de Sanidad Agropecuaria, el Arancel Externo Común, las normas sobre valoración aduanera, el transporte internacional de mercancías por carretera y por vía marítima, acciones por dumping y otras acciones relacionadas con el Régimen Común de Propiedad Industrial. ${ }^{26}$

Con ocasión de resolver los primeros procesos en Acción de Incumplimiento, el Tribunal dejó claramente establecidos los criterios sobre la naturaleza, el objeto y la finalidad de dicha acción, reconociendo que esta constituye el principal mecanismo de tutela de los objetivos del proceso de integración subregional andino y de los intereses comunitarios.

Del mismo modo, aseveró que es una acción jurisdiccional esencialmente contenciosa que se constituye como el medio idóneo para efectuar el control sobre las conductas y el cumplimiento de los compromisos y obligaciones asumidos por los Países Miembros, en el marco de las normas que conforman el ordenamiento jurídico comunitario andino. ${ }^{27}$

En relación con la Sentencia que emite en este tipo de acciones, el Tribunal aclaró que la misma: "no solo es declarativa en el sentido de limitarse a la mera declaración de la existencia de un derecho o de una obligación, sino que también está llamada a imponer el cumplimiento de una prestación de hacer o de no hacer" (sentencia proceso 01-AI-96).

En la segunda Sentencia emitida en una Acción de Incumplimiento, en el proceso 03-AI-96, el TJCA continuó la labor de definición de las características de dicha acción y así indicó que esta es "autónoma, propia,

26. En relación con las patentes de segundo uso, ver las sentencias recaídas en los procesos 89-AI-2000, 01-AI-2001 y 34-AI-2001 (Casos Viagra). En relación con la protección de los "datos de prueba", ver la Sentencia emitida en el proceso 114-AI-2004.

27. Ver Sentencias emitidas en los procesos 01-AI-96, 02-AI-96 y 03-AI-96. 
independiente y sui-géneris", la cual constituye además "una pieza clave en la construcción, desarrollo y vigencia del orden jurídico comunitario”. Por otra parte, en la Sentencia recaída en el proceso 51-AI-2000, el Tribunal calificó al proceso de integración andino como una verdadera Comunidad de Derecho y, por tanto, consideró que:

la obligatoriedad de cumplir la normativa comunitaria no surge como consecuencia de la emisión de un dictamen de incumplimiento o incluso de una sentencia que declare el incumplimiento por un País Miembro; es el principio de legalidad -más que el principio pacta sunt servanda, como ocurre en el Derecho Internacional-, el que exige que las relaciones entre los distintos sujetos del Derecho Comunitario -órganos e instituciones comunitarias, Países Miembros y ciudadanos de la Comunidad-, se rijan conforme al ordenamiento jurídico andino.

Del mismo modo, resulta importante destacar que en las acciones de incumplimiento se juzga esencialmente una conducta y no una norma jurídica; la cual, cuando existe, es solamente "un instrumento, un medio, para materializar la conducta objeto de censura", pues muchos incumplimientos "pueden darse incluso, sin que se profiera norma jurídica alguna" (sentencia proceso 07-AI-98).

Esta aclaración resulta de trascendental importancia en la construcción jurisprudencial de la figura del "incumplimiento continuado" que realizó el Tribunal, a partir del año 1998. Al efecto, este órgano comunitario efectuó un análisis encaminado a determinar la verdad material sobre las conductas que podrían configurar un incumplimiento y no se limitó a realizar un estudio formal sobre la vigencia de una norma nacional.

El leading case de esta línea jurisprudencial es el proceso 7-AI-98, en el que la SGCA demandó el incumplimiento de la República del Ecuador por aplicar niveles arancelarios diferentes a los previstos en el marco del Arancel Externo Común establecido en la Decisión 370 de la Comisión del Acuerdo de Cartagena. Durante el proceso, se evidenció que dicha conducta se habría instrumentalizado a través de tres Decretos Ejecutivos. Al respecto, la demanda se refería únicamente a la expedición del primero de ellos, el cual dejó de regir el 31 de diciembre de 1998, es decir un mes después de presentada la demanda ante el TJCA. En ese sentido, uno de los argumentos de la parte demandada fue que, a su juicio, se presentó el fenómeno de la sustracción de materia, pues la norma jurídica nacional que fue demandada, ya no se encontraba vigente. Sobre el particular, el Tribunal señaló lo siguiente: 
la conducta asumida por el gobierno ecuatoriano y calificada como de incumplimiento frente al Arancel Externo Común por la Secretaría General, ha ido evolucionando para presentar en las distintas fases características y modalidades diferentes pero que, en esencia, denotan una misma direccionalidad y finalidad conductual de modificar unilateralmente dicho instrumento de la integración andina.

[...]

De esta manera y teniendo en cuenta lo dicho anteriormente, en el sentido de que la norma legal comprometida solamente es un instrumento para materializar determinada conducta que puede ser contraria o no a lo previsto en el orden comunitario, no cabe duda de que si tal norma se deroga o si se modifica, pero la conducta persiste o se transforma, haciéndose más gravosa o atemperándose en sus efectos, el incumplimiento subsiste con las características, se insiste, de un incumplimiento continuado" (sentencia proceso 07-AI-98).

El Tribunal se ha pronunciado sobre el incumplimiento continuado en los procesos 53-AI-2000, 50-AI-2002, 117-AI-2003, 118-AI-2003, 132 AI-2003, 117-AI-2004, 1-AI-2006 y 5-AI-2007, resaltando que, en todos ellos, se emitió sentencia declarando el incumplimiento del País Miembro correspondiente. Es evidente que la construcción de la figura del "incumplimiento continuado" busca asegurar el efectivo cumplimiento de los objetivos del proceso de integración andino, así como la debida observancia de los compromisos y obligaciones asumidas por los Países Miembros, garantizando además la aplicación y eficacia de las normas que conforman el ordenamiento jurídico comunitario.

Por otra parte, en relación con los aspectos sustantivos del Programa de Liberación, el Tribunal desarrolló una posición clara, sistemática y concordante en las sentencias emitidas dentro de los procesos 2-AI-96, 3-AI-96, 1-AI-97 y 2-AI-97, las cuales sentaron las bases sobre el entendimiento judicial acerca del objetivo, la importancia y la finalidad de la formación de una zona de libre comercio y un mercado ampliado. Al respecto, el Tribunal reconoció expresamente que el Programa de Liberación es uno de los pilares básicos del sistema de integración andino, constituye uno de los instrumentos fundamentales para alcanzar los objetivos del Acuerdo de Cartagena, y señaló que "mantenerlo y defenderlo es una necesidad para el robustecimiento del proceso".

En el mismo sentido se pronunció sobre el Arancel Externo Común, el cual en palabras del Tribunal representa "uno de los mecanismos decisivos para lograr los objetivos propuestos”, pues constituye junto con el Programa 
de Liberación, "el ámbito indispensable para la construcción del mercado ampliado". De esta manera, ambos mecanismos resultan ser "parte sustancial de la existencia del mercado andino" (Sentencia procesos 7-AI-98 y 16-AI-99).

En una sentencia posterior, dentro del proceso 16-AI-99, el Tribunal advirtió que el incumplimiento de las normas que regulan estos dos importantes mecanismos genera inseguridad jurídica, especialmente para los inversionistas provenientes de terceros países, crea condiciones inequitativas de competencia entre Países Miembros y desmerece la seriedad del proceso de integración andina hacia la Comunidad Internacional.

En relación con la liberalización de la oferta y la prestación del servicio de transporte internacional de mercancías por carretera, entendido como "uno de los instrumentos más eficaces para la consolidación del espacio económico subregional" (sentencia proceso 15-AI-2000), el Tribunal, en las sentencias dictadas dentro de los procesos 46-AI-99, 15-AI-2000 y 16-AI-2000, aseveró que dicha liberalización está destinada a garantizar la eficiencia de dicho servicio, en condiciones de libre competencia, reconociendo la libertad de tránsito de los vehículos habilitados y las unidades de carga debidamente registradas para tal actividad.

La liberalización del transporte de mercancías está directamente vinculada con los objetivos del proceso de integración andina y, en consecuencia, incluso la omisión de los Países Miembros al no garantizar el libre tránsito de los vehículos de transporte internacional y permitir, por ejemplo, que grupos de interés interrumpan o bloqueen el paso transfronterizo, configura un incumplimiento de las obligaciones previstas en la normativa andina.

Como se puede apreciar, en esta segunda etapa de labores del Tribunal se suscitaron varias controversias importantes, en gran medida como resultado del re-lanzamiento del proceso integracionista con la suscripción del Protocolo de Trujillo, a través del cual se pretendía implementar una agenda propia del Regionalismo Abierto $^{28}$ en los países andinos; así como,

28. Wilfred Ethier, "The New Regionalism"; Mikio Kuwayama, Open regionalism in Asia Pacific and Latin America: a survey of the literature; Germánico Salgado, El Grupo Andino de hoy, eslabón hacia la integración de Sudamérica (Quito: Corporación Editora Nacional/Universidad Andina Simón Bolívar, Sede Ecuador, 1998). Mikio Kuwayama, Open regionalism in Asia Pacific and Latin America: a survey of the literature (1999); José Briceño Ruíz, "Ejes y modelos en la etapa actual de la integración económica regional en América Latina", Estudios Internacionales 45, n. ${ }^{\circ} 175$ (2013): 9-39. 
en virtud del aggiornamento de la estructura institucional y, sobre todo, de la activa participación de la SGCA. De esta manera, el Tribunal tuvo la oportunidad de ratificar los principios del ordenamiento jurídico andino, establecer con claridad la naturaleza, el objeto y la finalidad de la Acción de Incumplimiento como el vehículo procesal que permite vigilar el comportamiento de los Países Miembros, con miras a garantizar la plena observancia de los compromisos y obligaciones asumidas en calidad de miembros de la Comunidad Andina.

Asimismo, el Tribunal tuvo la oportunidad de delinear aspectos trascendentales en cuanto al contenido y alcance del Programa de Liberación, el Arancel Externo Común, la Liberalización del servicio de transporte internacional de mercancías, el Régimen Común de Propiedad Intelectual, entre otros temas. En suma, durante este período, el Tribunal Andino coadyuvó sustancialmente con la construcción de una nueva visión de la integración subregional orientada hacia el establecimiento de un mercado ampliado, regulado fundamentalmente mediante normas comunitarias. La actuación del órgano judicial supranacional buscaba además brindar la suficiente predictibilidad, seguridad y estabilidad jurídica a los Países Miembros, los agentes económicos y los ciudadanos andinos en general.

\section{Tercer período (2007 - 2019)}

Los particulares impulsando el Sistema Andino de Solución de Controversias

En el marco de la estrategia de Regionalismo Abierto adoptada en el proceso de integración andino, corresponde recordar que, en la décima reunión del Consejo Presidencial Andino, realizada el 4 y 5 de abril de 1998 en la ciudad de Guayaquil, Ecuador, se acordó diseñar una "política exterior común y una estrategia comunitaria que permita la proyección de la Comunidad Andina en el contexto internacional". En esa misma reunión, se encomendó al Consejo Andino de Ministros de Relaciones Exteriores (CAMRE) que, entre otros, profundice el diálogo con los Estados Unidos, especialmente para que se establezca un Consejo Andino-Estadounidense sobre Comercio e Inversión. Posteriormente, en la décimo tercera reunión del Consejo Presidencial celebrada el 23 y 24 de junio de 2001, se instruyó al CAMRE impulsar la negociación de un acuerdo de asociación con la Unión Europea. 
El año 2004 tuvo una importancia decisiva en la definición de la estrategia andina sobre negociaciones comerciales con terceros países, pues el Consejo Presidencial, reunido en Quito, Ecuador, reconociendo las oportunidades y desafíos que conllevan las negociaciones bilaterales que están desarrollando los Países Miembros, manifestó su complacencia con las mismas y recomendó que en todo momento se resguarden los objetivos, mecanismos e instituciones establecidos en el Acuerdo de Cartagena. En ese sentido, se aprobó la Decisión $598^{29}$ sobre "Relaciones comerciales con terceros", que amplió la posibilidad de negociar bilateralmente con cualquier país, cuando no fuese posible concluir una negociación en bloque.

La Decisión 598 resultó premonitoria y ante la imposibilidad de concluir conjuntamente la negociación, Colombia y Perú suscribieron en 2006 sendos acuerdos de promoción comercial con Estados Unidos. Estos hechos marcaron el inicio de una nueva estrategia de inserción económica global de esos dos países, suscitaron la salida de Venezuela del proceso de integración y generaron un marcado antagonismo con la estrategia comercial de Bolivia y Ecuador.

La misma suerte corrieron las negociaciones con la Unión Europea, las cuales se habían iniciado en bloque en el año 2007 y, a partir de febrero del año 2009 continuaron en un formato sui generis denominado multipartes, el cual incluía inicialmente a los países de la Unión Europea, Colombia, Ecuador y Perú. No obstante, a fines de ese año, Ecuador se retiró de las negociaciones y el 26 de junio de 2012, y Colombia y Perú fueron los únicos países de la CAN en suscribir un acuerdo comercial con el bloque europeo en ese momento. Posteriormente, en 2014, Ecuador reinició las negociaciones con la Unión Europea y el 11 de noviembre de 2016 se suscribió el correspondiente Protocolo de Adhesión al Acuerdo Comercial multipartes, el cual entró en vigencia el 1 de enero de 2017.

A partir de ese momento y durante la siguiente década, las políticas comerciales de los dos bloques formados al interior de la Comunidad Andina avanzaron como los rieles de un tren, de forma paralela y sin la posibilidad de cruzarse. En efecto, Colombia y Perú se embarcaron en una serie de negociaciones comerciales bilaterales con sus principales socios comerciales, en cuanto Bolivia y Ecuador reforzaron su perspectiva contraria a los

29. Disponible en: http://www.comunidadandina.org/DocOficialesFiles/Gacetas/Gace1092.pdf. 
tratados de libre comercio. En efecto, entre 2006 y 2016, Colombia y Perú firmaron varios acuerdos comerciales bilaterales, aspecto que evidencia claramente la orientación de su política comercial hacia el Bilateralismo competitivo que incluía la suscripción de acuerdos comerciales asimétricos con países desarrollados de distintas latitudes.

Esta posición contrapuesta generó un impase que bloqueó la posibilidad de profundizar la integración económica en el concierto andino, así como las negociaciones en otras áreas. Ante esta situación, el Consejo Presidencial Andino decidió iniciar en el año 2011 un proceso de reingeniería del Sistema Andino de Integración.

Como resultado de dicho proceso se redujeron los temas y ámbitos de acción a cargo de la Comunidad, se eliminaron Comités y Grupos de trabajo ad hoc, se ordenó la reestructuración orgánico y funcional de la Secretaría General, se dispuso que se inicie un proceso que facilite la salida del Parlamento Andino del sistema, ${ }^{30}$ y, al 2019, aún estaba pendiente la conclusión de la reingeniería del sistema de solución de controversias.

La situación descrita tuvo un impacto directo en las acciones tramitadas ante el Tribunal, especialmente en relación con los incumplimientos demandados por la SGCA, pues si en la década pasada había promovido ochenta acciones, entre 2007 y 2019, como ya se mencionó, presentó únicamente dos demandas, una en el año 2007 y, la última, en el año 2008. Por otra parte, en ese mismo período, los particulares, personas naturales y jurídicas iniciaron treinta y ocho acciones de incumplimiento. Un aspecto que también llama la atención es que desde el año 2000, ningún país presentó demandas de esta naturaleza.

Por otra parte, una de las consecuencias de la denuncia del Acuerdo de Cartagena, por parte de Venezuela, fue que, a partir del año 2006, el TJCA quedó integrado por cuatro Magistrados. En ese sentido, la estructura orgánica, funcional y económica del órgano jurisdiccional de la CAN fue alterada y pese a las reiteradas solicitudes para que esa situación se resuelva por la vía legislativa, la solución nunca llegó. De esta manera, la imprevista e inédita situación de contar con un número par de Magistrados generó un enorme desafío, especialmente en relación con el quorum decisorio, ya

30. Ver la Decisión 792 del Consejo Andino de Ministros de Relaciones Exteriores, reunido en forma ampliada con los Representantes Titulares ante la Comisión de la Comunidad Andina. 
que naturalmente podría presentarse un empate durante la deliberación y posterior votación de providencias y sentencias.

Sobre el particular, en el mes de enero del año 2014, el Tribunal recibió una demanda laboral (Proceso 01-DL-2014) y después de la deliberación sobre su admisibilidad no fue posible alcanzar consenso. El resultado de la votación fue de dos votos a favor de la admisión de la demanda y dos votos por el rechazo in límine. Este hecho generó que el Pleno del Tribunal iniciara una profunda reflexión acerca del problema derivado de su composición par, concluyendo que de ninguna manera la omisión legislativa podía impedir la oportuna administración de justicia y la eficaz tutela jurisdiccional. El Tribunal consideró además que la inacción frente a una laguna normativa vaciaría de contenido su misión esencial de administrar justicia y colocaría a los ciudadanos andinos en una situación de total indefensión.

Como resultado de intensos debates al interior del Tribunal, el 13 de mayo de 2014 se aprobó por mayoría la Resolución 01/2014 "Procedimiento para resolver la falta de quorum decisorio en asuntos judiciales". En dicha Resolución, se utilizó la integración del derecho como un mecanismo para superar los efectos del vacío normativo mencionado anteriormente. En ese sentido, el Tribunal realizó una interpretación teleológica y sistemática de los artículos 13, literal d) y 70 de su Estatuto, con el objeto de evidenciar que, únicamente cuando el impedimento o recusación del Magistrado titular (situación fáctica) genere una afectación sustancial al proceso y no sea posible alcanzar el quorum deliberatorio o decisorio (consecuencia jurídica), el Tribunal debe convocar a un Magistrado suplente (solución normativa). Es decir, la convocatoria de un Magistrado suplente no responde a una determinada situación fáctica, sino que está justificada por las consecuencias prácticas y jurídicas de dicha situación.

El Tribunal entendió que el empate en la votación (situación fáctica) generaba la misma consecuencia jurídica de falta de quorum deliberatorio y decisorio y, por tanto, debería aplicarse la misma solución normativa de convocar a un Magistrado suplente. ${ }^{31}$ Así, sería posible dirimir el empate, alcanzar el quorum decisorio requerido y cumplir su principal misión de administrar justicia. La Resolución 01-2014 ha sido aplicada diversas veces

31. De acuerdo con el artículo segundo de la Resolución 01-2014, el TJCA realiza anualmente un sorteo público entre los primeros Magistrados suplentes de cada País Miembro, a fin de establecer el orden de intervención de cada uno de ellos en los procesos en que sea aplicable dicha Resolución. 
desde su entrada en vigencia, asegurando de esta manera la oportuna administración de justicia y evitando la parálisis del sistema.

De otro lado, es importante señalar que, en la más reciente fase de labores del Tribunal, la Interpretación Prejudicial -mecanismo de colaboración judicial esencial de la comunidad de derecho que representa la Comunidad Andina-, ha sido la principal protagonista. En efecto, entre 2007 y 2019 no solo se incrementaron exponencialmente el número de solicitudes (4701) como la cantidad de Interpretaciones Prejudiciales emitidas por el Tribunal (4194). ${ }^{32}$

Al respecto, en el año 2014,,$^{33}$ el Pleno del TJCA decidió llevar adelante un diálogo franco y directo con las autoridades judiciales que utilizan este mecanismo, así como con las entidades administrativas nacionales que aplican su jurisprudencia. Esta iniciativa permitió que los Magistrados juntamente con las autoridades nacionales realizaran una adecuada evaluación sobre la forma en que se estaba aplicando la norma andina y las Interpretaciones Prejudiciales en la solución de casos en sede nacional.

De esta manera fue posible identificar aspectos procesales y cuestiones sustanciales que podrían optimizar su labor. Del mismo modo, en cumplimiento de una de las funciones más importantes del Tribunal de realizar actividades de difusión del ordenamiento jurídico comunitario andino, entre los años 2015 y 2019, este órgano comunitario organizó y participó en ciento veintisiete eventos y actividades de esta naturaleza en los cuatro países miembros. ${ }^{34}$

Un resultado concreto del trabajo realizado en los países fue la solicitud de interpretaciones prejudiciales, presentada casi simultáneamente por el Servicio Nacional de Propiedad Intelectual del Estado Plurinacional de Bolivia (Proceso 105-IP-2014) y la Dirección de Signos Distintivos del Instituto Nacional de Defensa de la Competencia y de la Propiedad Intelectual de la República del Perú (Proceso 121-IP-2014). Ambas consultas permitieron que el Tribunal realice un aporte fundamental al derecho co-

32. De acuerdo con la información proporcionada por la Secretaría del Tribunal de Justicia de la Comunidad Andina.

33. Ver Informe de Labores de la gestión 2014 del Tribunal Andino. Disponible en: https://www.tribunalandino.org.ec/wp-content/uploads/2019/04/INFORME2014.pdf

34. De acuerdo con la información proporcionada por la Secretaría del Tribunal de Justicia de la Comunidad Andina. 
munitario andino, toda vez que en los dos casos se reconoció la legitimidad activa de los solicitantes.

De esta manera, las entidades administrativas permanentes, constituidas por mandato constitucional o legal, que acrediten el carácter obligatorio de sus competencias, el deber de aplicar normas andinas, el carácter contradictorio de los procedimientos a su cargo, así como el respeto al debido proceso y su independencia y autonomía funcional, tienen la facultad de solicitar una Interpretación Prejudicial.

El análisis que realizó el TJCA partió de la premisa de que el término juez nacional contenido en los artículos 33 del Tratado de creación del Tribunal y 122 y 123 de su Estatuto, es un concepto autónomo del derecho comunitario andino que debe ser definido por el propio Tribunal, tomando en cuenta el objeto y la finalidad del instituto de la Interpretación Prejudicial.

Así, para asegurar la aplicación uniforme del derecho andino se debe tomar en cuenta que el mismo no solamente se aplica en sentencias judiciales, sino también en actos administrativos que reconocen o deniegan derechos, y resuelven controversias. El Tribunal reconoció que la independencia de las entidades que emiten dichos actos promovió la jurisdiccionalización de los procedimientos que tramitan, en los que se observan las garantías del debido proceso. Asimismo, consideró que, de acuerdo con el principio de legalidad, el límite de actuación de las administraciones nacionales también está determinado por el ordenamiento jurídico comunitario andino.

En ese sentido, si las entidades competentes cuentan con una Interpretación Prejudicial antes de emitir un acto administrativo, se garantiza la "aplicación uniforme de la norma comunitaria desde el primer momento en que es invocada", reduciendo así la discrecionalidad de la administración y otorgando mayor predictibilidad, seguridad jurídica y protección de los derechos de los administrados.

Este avance jurisprudencial que profundizó lo que ya se había hecho en los procesos 14-IP-2007, 130-IP-2007 y 03-AI-2010, sirvió posteriormente de base para la emisión de los Acuerdos 08/2017 y 04/2018 que establecen el Reglamento que regula aspectos vinculados con la emisión y solicitud de Interpretaciones Prejudiciales, en el que, entre otros, se establece la posibilidad de que las partes en los procesos internos formulen preguntas, presenten informes técnicos o normativos, y participen en informes orales, en el marco de una solicitud de Interpretación Prejudicial. Estas decisiones 
permiten un mayor y mejor acceso de los particulares al mecanismo andino de solución de controversias.

Debe tomarse en cuenta que, a diferencia de lo que ocurre con las Acciones de Incumplimiento que son planteadas ante la inobservancia de los compromisos y obligaciones asumidas por los Países Miembros; o, las Acciones de Nulidad que promueven un control de legalidad sobre las actuaciones de los Órganos del Sistema Andino de Integración con competencia legislativa; las consultas de Interpretación Prejudicial son formuladas en el marco de procesos nacionales en los que, precisamente se aplican las normas andinas y se están discutiendo los derechos de los ciudadanos andinos, así como los intereses de los agentes económicos que participan en el mercado ampliado, reconocidos en el ordenamiento jurídico comunitario.

Es decir que, es evidente que el incremento exponencial de consultas, así como el desarrollo jurisprudencial del Tribunal Andino, en ejercicio de esta competencia, promueven una mayor eficacia de las normas andinas, y en definitiva constituyen un aporte esencial para la continuidad del proceso de integración.

Por otra parte, la ampliación de las materias que son objeto de consulta, vía Interpretación Prejudicial, es una clara muestra de que la armonización legislativa prevista en el Acuerdo de Cartagena, no se limita a la adopción de normas comunitarias, sino que estas son efectivamente aplicadas por las autoridades administrativas y judiciales de los Países Miembros. En ese sentido, al margen de los temas vinculados con el Programa de Liberación y los Regímenes Comunes de Propiedad Industrial y Derechos de Autor, en los últimos años, el Tribunal ha desarrollado una prolija jurisprudencia sobre otros temas, tales como: Libre competencia, normas de origen, temas aduaneros, derecho tributario, transporte, telecomunicaciones y minería ilegal.

\section{Consideraciones finales}

La integración económica regional entendida como un proceso y como los resultados que se obtienen durante su desarrollo, dista mucho de ser una simple sucesión de fases por las que se debe transitar según una hoja de ruta predeterminada, con el propósito de alcanzar metas de forma lineal y homogénea. Del mismo modo, los actores públicos y privados que intervienen en su formación y funcionamiento no responden únicamente 
a variables económicas y comerciales de carácter sistémico, sino que actúan tomando en consideración las demandas internas que incluyen aspectos políticos, jurídicos y sociales.

La institucionalización y legalización $n^{35}$ de un proceso de integración que incluye obligaciones vinculantes, reglas claras y precisas, y la delegación del control de legalidad- no determina, por sí misma, el éxito o el fracaso de una iniciativa regional. No obstante, tomando en cuenta su naturaleza instrumental, el grado en el que se implementan, mantienen y consolidan, incide directamente en el avance y retroceso del proceso en su conjunto o de algunas áreas o temas específicos.

El cambio cualitativo hacia la legalización en el proceso de integración subregional andino, con el consecuente perfeccionamiento de la supranacionalidad, se produjo en 1983, con la entrada en vigencia del Tratado de Creación del Tribunal de Justicia del Acuerdo de Cartagena. En ese momento, surgió una nueva Comunidad de Derecho que encuentra fundamento, por una parte, en el reconocimiento expreso de la existencia y vigencia de un ordenamiento jurídico autónomo, vinculante, de aplicación inmediata y eficacia directa, que prevalece además sobre otras normas internas e internacionales; y, por otra, en la delegación del ejercicio de competencias jurisdiccionales -control de legalidad, cumplimiento y de interpretación y aplicación uniforme de la normativa andina- a un órgano judicial permanente.

El Protocolo de Trujillo de 1996, modificatorio del Acuerdo de Cartagena, y el Protocolo de Cochabamba de 1998, modificatorio del Tratado de Creación del Tribunal de Justicia, complementaron y elevaron el nivel de institucionalización y legalización, al establecer el Sistema Andino de Integración como la estructura orgánica e institucional del proceso, y otorgar más facultades al Tribunal Andino, respectivamente.

La evidencia empírica demuestra que el establecimiento de normas de obligatorio cumplimiento y de un avanzado mecanismo de control, no tuvo efectos inmediatos ni automáticos. Por el contrario, durante los primeros once años de implementación de dicho mecanismo, este tuvo una incidencia modesta en el devenir del proceso, explicada fundamentalmente por la inacción de los países miembros, principales destinatarios de las normas andinas.

35. Kenneth Abbott, et al, "The concept of legalization". 
No obstante, la escasa utilización del sistema de solución de controversias, es evidente que el Tribunal Andino aprovechó cada oportunidad para establecer, en primer lugar, el fundamento sobre los métodos funcionales que utilizaría para interpretar las normas comunitarias; y, en segundo lugar, aplicando esos métodos, sentar las bases de los principios y características del derecho comunitario andino, entre los que destaca, el principio de cooperación leal.

Del mismo modo, en sus primeras sentencias definió el contenido, objeto y alcance de las disposiciones que regulan el Programa de Liberación y el Régimen Común de Propiedad Industrial. Esas dos temáticas marcarían, a la larga, la pauta de la labor jurisdiccional en la Comunidad Andina.

La experiencia demuestra además que un ordenamiento jurídico no solamente es eficaz en la medida en que sus destinatarios cumplen con sus disposiciones, sino también adquiere eficacia cuando es posible acudir a un mecanismo independiente, autónomo y especializado, en caso de incumplimiento, con el propósito de obtener la debida tutela judicial.

En ese sentido, los mayores aportes del Tribunal Andino para la consolidación de los objetivos del proceso de integración, especialmente en relación con el Programa de Liberación y el Arancel Externo Común, se dieron como resultado de las acciones de incumplimiento propuestas por la SGCA y, en menor medida, por los Países Miembros y los particulares entre 1996 y 2006. Esta dinámica coincide con el período de ampliación y profundización de las políticas comunes y el acervo normativo en la Subregión, lo cual, sumado a la actividad jurisdiccional, generó un escenario propicio para que se produzca, durante ese período, un efectivo avance en esas áreas temáticas.

Por otra parte, ante un nuevo período de relativa inacción de la SGCA y de los Países Miembros, han sido las personas naturales y jurídicas quienes actuando directamente ante el sistema andino de solución de controversias o acudiendo a las instancias nacionales pertinentes, han promovido la continuidad en la aplicación de las disposiciones andinas, lo que se traduce en una verdadera armonización de las políticas económicas.

En efecto, dicha armonización no se limita al establecimiento de normas comunes, sino que, ante todo, está destinada a su efectiva implementación en los Países Miembros, para lo cual se requiere el concurso de todas las autoridades administrativas y judiciales involucradas en su diseño 
y ejecución. En ese sentido, la Interpretación Prejudicial resulta de vital importancia, pues es el mecanismo de colaboración idóneo -entre las autoridades nacionales y el Tribunal comunitario- para asegurar la interpretación y aplicación uniforme de las normas andinas. Es precisamente, a través del ejercicio de esa competencia, que el Tribunal ha construido una sólida jurisprudencia en diversas áreas temáticas, entre las que resalta la propiedad intelectual.

De esta manera, resulta evidente que la construcción del acervo normativo comunitario, así como el control de legalidad, cumplimiento e interpretación y aplicación uniforme, son parte de un proceso -institucionalización y judicialización- dinámico, heterogéneo y multicausal. Asimismo, se aprecian diferentes niveles de cumplimiento de los compromisos y obligaciones asumidas por los Países Miembros, así como diversos grados de utilización de los mecanismos judiciales nacionales y comunitarios, por parte de los actores públicos y privados.

En ese contexto, el Tribunal de Justicia de la Comunidad Andina ha desempeñado diversos roles en los cincuenta años de integración subregional, desde el establecimiento de las bases del derecho comunitario y del propio proceso de integración, pasando por la definición de los contornos de los principales mecanismos para la consolidación de un mercado ampliado, y coadyuvando con la armonización de políticas económicas.

\section{Bibliografía}

Abbott, Kenneth, Robert Keohane, Andrew Moravcsik, Anne-Marie Slaughter y Duncan Snidal. "The concept of legalization". International organization 54, n. 3 (2000): 401-19. doi:10.1162/002081800551271

Balassa, Bela. The Theory of Economic Integration. New York: Routledge, 1961.

Baldwin, Richard. "The Causes of Regionalism". The World Economy 20, n. 7 (1997): 865-888. doi:10.1111/1467-9701.00107

Banco Mundial. "Trade blocs. A World Bank Policy Research Report". Washington, D.C.: The World Bank

Bhagwati, Jagdish. "Regionalism and Multilateralism: an overview". En New dimensions in regional integration, editado por Jaime de Melo, 22-51. Cambridge: Cambridge University Press, 1993.

Bown, Chad, Daniel Lederman, Samuel Pienknagura y Raymond Robertson. Mejores vecinos. Hacia una renovación de la integración económica en América Latina. Washington D.C.: Banco Mundial, 2017. ‘https://bit.ly/34P8UYx〉. 
Braga, Primo, Raed Safadi y Alexander Yeats. "Regional integration in the Americas: deja vu all over again?". The World Economy 17, n. ${ }^{\circ} 4$ (1994): 577-602. doi:10.1111/j.1467-9701.1994.tb00842.x

Briceño Ruíz, José. "Ejes y modelos en la etapa actual de la integración económica regional en América Latina”. Estudios Internacionales 45, n. ${ }^{\circ} 175$ (2013): 9-39. doi:10.5354/0719-3769.2013.27352

Casas, Ángel María. El modelo regional andino. Enfoque de economía política internacional. Quito: Universidad Andina Simón Bolívar / Abya-Yala / Corporación Editora Nacional, 2003.

Comisión Económica para América Latina. El regionalismo abierto en América Latina y el Caribe: la integración económica al servicio de la transformación productiva con equidad. Santiago de Chile: CEPAL, 1994. 〈https://bit.ly/30ZUyDE〉.

Devlin Robert y Antoni Estevadeordal. ¿Qué hay de Nuevo en el Nuevo Regionalismo de las Américas?. Buenos Aires: INTAL / ITD / STA, 2001. «https://bit. ly/33PTmVk>.

Ethier, Wilfred. "The New Regionalism”. The Economic Journal 108, n. 449 (1998): 1149-61. doi:10.1111/1468-0297.00335

Furtado, Celso. "Dependencia externa y teoría económica". El trimestre económico 38, n. ${ }^{\circ} 150(1971): 335-49$.

Haas, Ernst. "The study of regional integration: reflections on the joy and anguish of pretheorizing". International organization 24, n. ${ }^{4}$ (1970): 607-46. doi:10.1017/ S0020818300017495

Keohane, Robert. "Cooperation and international regimes". En After Hegemony: Cooperation and Discord in the World Political Economy, 49-13. New Jersey: Princenton University Press, 1984. doi:10.2307/j.ctt7sq9s.7.

Krasner, Stephen. "State power and the structure of international trade". World politics: A quarterly journal of international relations 28, n. 3 (1976): 317-47. doi:org/10.2307/2009974

Krugman, Paul."Regionalism versus multilateralism: analytical notes”. En New dimensions in regional integration. Editado por Jaime de Melo y Arvind Panagariya, 58-79. Cambridge: Cambridge University Press, 1993.

Kuwayama, Mikio. Open regionalism in Asia Pacific and Latin America: a survey of the literature. Santiago de Chile: CEPAL, 1999.

Malamud, Andres. "Conceptos, teorías y debates sobre la integración regional". Ponencia presentada en el V Congreso Latinoamericano de Ciencia Política, Buenos Aires, 28 al 30 de julio de 2010.

Malamud, Andrés y Philippe Schmitter. "La experiencia de integración europea y el potencial de integración del Mercosur”. Desarrollo Económico 46, n. ${ }^{\circ} 181$ (2006): 3-31. doi: 10.2307/4151099

Mantilla, Galo. Derecho andino. Quito: Tribunal de Justicia del Acuerdo de Cartagena, 1992. 
Mattli, Walter. The logic of regional integration: Europe and beyond. Cambridge : Cambridge University Press, 1999.

Mansfield, Edward y Helen Milner, ed. The political economy of regionalism. Columbia: Columbia University Press, 1997.

Montaño Galarza, César. Problemas constitucionales de la integración. Mexico D.F.: Universidad Anáhuac / Porrúa / Red Internacional de Juristas para la Integración Americana / Universidad Andina Simón Bolívar, 2013.

Nye, Joseph S. "Comparative regional integration: Concept and measurement", International organization 22, n. ${ }^{\circ} 4$ (1968): 855-80. https://www.jstor.org/stable/2705847?.

Prebisch, Raúl. Hacia una dinámica del desarrollo latinoamericano: con un apéndice sobre. El falso dilema entre desarrollo económico y estabilidad monetaria. México: Fondo de cultura económica, 1963. ‘https://bit.ly/33RUdEK».

Quiliconi, Cintia. "Modelos competitivos de integración en el Hemisferio Occidental: ¿Liderazgo competitivo o negación mutua?". Revista CIDOB d'afers internacionals, n. ${ }^{\circ} 102-103$ (2013): 147-68. https://bit.ly/3dnluCc'.

Quindimil, Jorge Antonio. Instituciones y derecho de la Comunidad Andina. Valencia: Tirant lo blanch, 2006.

Reynolds, Clark, Fransico Thoumi y Reinhart Wettmann. A Case for Open Regionalism in the Andes. Policy Implications of Andean Integration in a Period of Hemispheric Liberalization and Structural Adjustment. Washington: USAID / Friedrich Ebert Stiftung, 1995.

Sáchica, Luis. Introducción al derecho comunitario andino. Bogotá: Temis, 1990.

Salazar Manrique, Roberto. "El derecho Comunitario Andino: de la teoría Jurídica a la realidad actuante del derecho". Revista Jurídica, n. 9 (1994): 247-96. ‘https:// bit.ly/3lGNC6s'.

Salgado, Germánico. El Grupo Andino de hoy, eslabón hacia la integración de Sudamérica. Quito: Corporación Editora Nacional / Universidad Andina Simón Bolívar, Sede Ecuador, 1998.

Summers, Lawrence. "Regionalism and the world trading system". Policy implications of trade and currency zones (1991):295-301. https://bit.ly/3dnnlXG.

Vigil Toledo, Ricardo. La estructura jurídica y el futuro de la comunidad andina. Madrid: Civitas, 2011.

Vivares, Ernesto, Paul Torres y Kristina Cvetich. "Enfoques y cárceles conceptuales en el entendimiento de los Nuevos Regionalismos Latinoamericanos". En Desafíos estratégicos del regionalismo contemporáneo: CELAC e Iberoamérica, editado por Adrián Bonilla e Isabel Álvarez, 21-47. San José: FLACSO, 2014.

Zelada Castedo, Alberto. Derecho de la integración económica regional. 2 vols. Buenos Aires: Ediciones de Palma, 1982. 